\title{
LA HOTELERÍA EN EL ANTIGUO MAGALLANES (1870-1950)
}

MATEO MARTINIC B.*

\section{RESUMEN}

Se da cuenta sobre el origen y desarrollo de la hotelería en Magallanes, tanto en el ámbito urbano como en la zona rural, poniéndose de relieve su importancia económica, con diferentes características, y en especial su significación social, lo que contribuyó a perfilar la vida y la actividad productiva en el período histórico comprendido entre el cuarto final del siglo XIX y la mitad del siglo XX.

\section{HOSTELRY IN THE OLD MAGELLAN TERRITORY (1870-1950)}

\begin{abstract}
Information about the origin and development of hostelry in Magallanes, including its role in urban and countryside contexts, is used to underscore its economic importance and, especially, its social meaning as part of lifestyles and productive activities between the end of the $19^{\text {th }}$ century and the first half of the $20^{\text {th }}$ century.

\section{INTRODUCCIÓN}

En la historia humana, a contar de la época más remota en que aparecieron las sociedades sedentarias, ha sido común desde tiempo inmemorial la práctica del servicio de hospedaje. Iniciado sin duda como un acto humanitario ante un requerimiento de cobijo ocasional por parte de viajeros, de lo que la Biblia contiene algunas referencias, con el transcurrir de los siglos y en la medida que la evolución y organización sociales lo fueron requiriendo, dicha práctica devino un servicio oneroso, de carácter mercantil. Surgieron así las posadas u hospederías tanto en los centros urbanos como a la vera de los

caminos, para acoger a los que necesitaban de un alojamiento transitorio.

Es condición esencial para la vigencia de tal servicio la libertad de movimiento de las personas y un cierto grado de desarrollo económico en el entorno como para justificar viajes a distancia que hagan exigible tal práctica. De allí que faltando los mismos no ha podido darse aquél. Fue lo ocurrido en la Colonia de Magallanes durante su fase o etapa inicial, esto es, la de un mero establecimiento penal-militar, circunstancia que exigía la presencia de autoridades, guardia militar y los penados, en ocasiones acompañados por sus familiares. En buenas cuentas, se trataba de un asentamiento

* Centro de Estudios del Hombre Austral, Instituto de la Patagonia, Universidad de Magallanes. Casilla 113-D, Punta Arenas, Magallanes.
\end{abstract}


en el que nadie permanecía por la sola voluntad, excepto quizá los últimos, y a los que mantenía el Estado con remuneraciones y raciones en un caso, y sólo raciones en otro. Queda a la vista que no se daban entonces las condiciones favorables para la prestación del servicio de hospedaje, pues no se contaba ni con la disposición oficial ni se disponía de incentivos que contribuyeran a fomentar la presencia de colonos libres, indispensable para la generación de actividades económicas. De esa manera transcurrió el lapso comprendido entre 1843 y 1868 que hemos calificado como "del letargo colonial" en algunos de nuestros trabajos (Martinic 1988 y 1992a).

\section{El hospedaje informal 1870-1880}

La situación descrita hubo de mutar a contar de 1868 una vez que el gobierno de la República advirtió que el rumbo que llevaba la impropiamente llamada "Colonia" de Magallanes no tenía destino y que urgía adoptar algunas decisiones importantes que alteraran significativamente el estado de cosas conocido. En síntesis, dichas medidas fueron el otorgamiento de facilidades para la colonización libre y la llegada de inmigrantes, la declaración de zona libre de aduanas y de puerto menor para Punta Arenas, y la designación del capitán de corbeta Oscar Viel, de la Armada de Chile, como gobernador de Magallanes. Estas disposiciones, todas felices, distinguirían para la historia al gobierno del Presidente José Joaquín Pérez, y en su conjunto sirvieron para reorientar la evolución del establecimiento colonial de Magallanes, con un sentido de franco y sorprendente adelanto.

Como consecuencia, hacia 1870 Punta Arenas pasó a mostrarse cada vez con mayor definición como una comunidad progresivamente laboriosa, que crecía en población y actividades.

Esta circunstancia debió conducir al supuesto histórico al que se ha hecho referencia en el parágrafo introductorio, como efectivamente sucedió. Es decir, hubo movimiento de personas bien ingresando a la colonia, bien trasladándose hacia o retornando desde su vastísimo hinterland, lo que hizo posible el surgimiento del servicio de hospedaje como una necesidad social y una función económica, claro está que con carácter informal e inorgánico.

Sensiblemente, este tipo de actividad no es fácilmente identificable en sus comienzos y por ello faltan por completo los antecedentes que pudieran dar cuenta de su origen y desarrollo inicial. La primera referencia se tiene para el año 1877 y procede de la relación de sus aventuras que dejara Julius Beerbohm, con el título de Wanderings in Patagonia (London, 1879).

En efecto, cuenta este viajero que al arribar a Punta Arenas el 10 de noviembre del año mencionado al cabo de un azaroso recorrido iniciado semanas antes en el puerto de San Julián, en la costa atlántica, debió necesitar de modo apremiante de un sitio en donde asearse, alimentarse, descansar y reponerse tras las muchas fatigas del viaje. Seguramente al llegar a la colonia inquirió por un lugar donde hospedarse y se le hizo la recomendación del caso.

No hay posadas en Punta Arenas, relataría después, los visitantes son de rara ocurrencia, así que llegamos a la casa de un austríaco, llamado Pedro, quien antiguamente había sido un traficante con los indios y ahora tenía un pequeño almacén. Después de haber disfrutado de la lujuria de un baño caliente y una afeitada, y habiendo hecho algunos cambios notables en mi vestimenta $y$ aspecto, me senté a comer con Pedro. El estrago que hice entre quesos, mantequilla fresca, pan, mermelada, etc. fue tremendo.

[...] Después de cenar no demoré en irme a la cama. Llevaba quince horas montado a caballo y estaba suficientemente fatigado como puede suponerse ${ }^{1}$.

Aquí tenemos la primera y valiosa referencia descriptiva de un establecimiento de hospedaje en Punta Arenas, de funcionamiento ciertamente elemental aunque satisfactorio para el tiempo y el medio.

Cabe abundar sobre su propietario. Este no era otro que Pedro Zambelic, croata de la provincia de Dalmacia, y como tal súbdito de la corona de Austria en el Imperio Austro-Húngaro, quien había arribado como inmigrante hacia 1870. Como tantos otros foráneos había tenido distintas ocupaciones, entre ellas la aventurera pero lucrativa del tráfico con los aónikenk, aborígenes de la Patagonia oriental, y así había acabado por establecerse con un despacho o boliche, donde tenía su vivienda y brindaba el servicio de hospedaje ocasional. Éste, al parecer era tan bueno como para satisfacer las

1 Op. cit., págs. 227 y 228. Traducción nuestra. 
necesidades de aseo, alimentación y reposo, a juzgar por el testimonio transcrito.

Así fue que tras ese alojamiento satisfactorio, no obstante que su descanso durante la primera noche fuera abrupta e imprevistamente interrumpido ${ }^{2}$, al retornar a Punta Arenas algo más de un año después Beerbohm volvió al establecimiento de Zambelic. Por lo demás, al parecer, no había dónde más elegir. Con él venía un grupo de nobles ingleses, Lord y Lady Dixie, el marqués de Queensberry y Lord James Douglas, que habrían de ser protagonistas del primer viaje turístico en la Patagonia austral ${ }^{3}$.

No era un lugar ambicioso, recordaría más tarde Florence Dixie. Su interior consistía en un piso de tierra ${ }^{4}$ con dos habitaciones, de las cuales una servía como almacén y la otra como sala de estar. Este último lugar lo aseguramos para guardar nuestro equipaje y maletas y allí también comimos durante nuestra estadía en Punta Arenas. La parte superior de esta magnífica residencia, agregaría con ironía, era una especie de desván, en uno de cuyos rincones había un pequeño compartimiento que mi hermano y el señor Beerbohm usaron como dormitorio ${ }^{5}$.

Aunque para la exigente dama de tanta alcurnia como era Lady Dixie la impresión que de entrada le hizo la posada de Pedro fue más bien desagradable, no ocurrió lo mismo al retornar de la aventura exploratoria, cuando "la magnífica residencia" fue valorada como satisfactorio lugar de alojamiento tras las penurias soportadas por más de un mes en la naturaleza. Como puede verse, todo fue relativo y dependió de si se procedía del elegante camarote de primera clase de un paquebote de la Pacific Steam Navigation Co., o de campo abierto.

Las consignadas son las únicas referencias conocidas para la posada de Pedro Zambelic, de hecho el primer establecimiento hotelero en la historia puntarenense, aunque informal. Así lo calificamos pues está claro que era un servicio de circunstancias, hechizo, cual podía esperarse en un

2 Esa noche se inició el conocido como "Motín de los Artilleros", de lamentables consecuencias en vidas humanas perdidas $y$ en bienes destruidos.

3 Véase Florence Dixie, A través de la Patagonia, Ediciones de la Universidad de Magallanes, Punta Arenas, 1996.

4 Esta afirmación nos merece dudas porque esta práctica no era común en la época.

5 Op. cit., pág. 46. poblado de frontera colonizadora que recién iniciaba su desarrollo.

No nos ha sido posible determinar con precisión el lugar donde se situaba la posada de Pedro. Sólo sabemos por la referencia posterior de Florence Dixie que estaba a unas 200 yardas del muelle por el que desembarcaban los pasajeros. Como en la época el plano inferior de la actual ciudad, que se extiende desde la calle Lautaro Navarro al oriente aún no estaba ocupado, ello significa que habría que situarla quizá sobre el eje de la actual calle 21 de Mayo que se halla a una distancia semejante de la playa, más precisamente entre las calles Errázuriz y Roca (Coquimbo y Concepción en la época), siendo aquélla el acceso más corriente a la zona poblada. Se nos antoja que quizá fuera una de las casas de planta baja y altillo que se levantaba sobre la acera oriente de la calle, y que se muestra en la fotografía superior de la página 232 de nuestra obra referida a Punta Arenas ${ }^{6}$.

\section{La hotelería formal}

\section{a) La hotelería urbana (Punta Arenas, Porvenir y Puerto Natales)}

\section{a.1 Período 1880-1920}

Pasada la década de 1870 , suerte de período precursor en la materia, hay constancia del funcionamiento de un establecimiento hotelero en forma iniciado en los años de 1880. Se trata del "Hotel del Puerto" de propiedad de los comerciantes españoles José Menéndez y José Montes. La evidencia la hemos obtenido de una factura que obra en el Archivo de José Nogueira, documento que, como era común en la época, publicita todas sus ofertas, en el caso comidas, fiambres, licores, comestibles, loza, cristales ${ }^{7}$. Esa mezcla entre hotel, restorán y almacén de ramos generales era cosa común en ese tiempo en que, a lo menos en Punta Arenas, solían combinarse rubros mercantiles diversos, algunos tan curiosos como "carnicería y billares" .

$6 \quad$ Punta Arenas en su primer medio siglo 1848-1898(Punta Arenas, 1988).

7 M. Martinic, José Nogueira, primer pionero y hombre de fortuna de la antigua Colonia de Magallanes, Anales del Instituto de la Patagonia, volumen II, Punta Arenas, 1971. Id. pág. 56. 
Nada más se sabe sobre este hotel y debiera suponerse que su vigencia no superó la década.

Un asiento notarial de mediados de los años 80 nos brinda la información sobre un segundo establecimiento, el Hotel "Unión", que era regentado por el francés Francisco Aubry, al parecer como actividad anexa a su negocio artesanal de panadería. En efecto, por escritura pública de 5 de setiembre de 1885, Elías y Mauricio Braun compraron a Aubry en 800 libras esterlinas la Panadería "Francesa" y el Hotel "Unión", incluyéndose en la venta el sitio donde se ubicaban ambos, las construcciones, horno, material "y la clientela" como reza textualmente el documento. De aquí entendemos la temprana fama que tuvo Elías Braun como empresario del ramo. Pasado 1890, Punta Arenas inició un crecimiento acelerado y hasta sorprendente gracias al arribo de numerosos inmigrantes europeos, en buena parte de origen croata, animados por la explotación aurífera de las islas del sur del canal Beagle, y por la multiplicación de emprendimientos económicos de diverso género, y todo ello en el contexto de un impresionante desarrollo de la colonización por toda la zona oriental de Magallanes, desde los valles andinos de Última Esperanza hasta el interior de la isla grande de Tierra del Fuego, y en la zona patagónica continental centro-oriental, gracias al exitoso crecimiento de la crianza ovejera, la actividad que dinamizaba el progreso.

Así, la presencia creciente de forasteros y de gente que procedía del interior del territorio era garantía más que suficiente de clientela para los establecimientos del ramo hotelero, que no demoraron en abrirse y multiplicarse porque, claro está, era también un buen negocio para quien tuviera alguna experiencia previa y un pequeño capital.

Para entonces (enero de 1894) ya circulaba el periódico El Magallanes, a través de cuyas páginas y de otros antecedentes es posible tener una idea acerca de la evolución del ramo durante la década final del siglo XIX. De ese modo aparecen tempranamente mencionados los hoteles "Comercial", de Torres y Docherty, "Universal" de Ríos y Docherty, "Bella Dalmacia", de Marcos Pivcevic, "Caledonia" de J. C. Robins y "de Londres", propiedad de otro súbdito británico, y "Kosmos". Este último que desde un principio fue tenido como un hotel de primera categoría, fue fundado por $\mathrm{H}$. Groenewold, un antiguo capitán mercante de la Compañía Naviera Alemana Kosmos, de la que tomó nombre el establecimiento, y que fue abierto al público el 1 de abril de 1894 .

En los años siguientes se mencionan los hoteles "de la Marina" y "Pacífico", nuevas denominaciones para los antiguos "Londres" y "Comercial", siendo el primero propiedad de José Burgos y el segundo de la firma F. Steffens y Cía. También comenzaron a funcionar por entonces el "Hotel de France", de propiedad de Raymond Mounot; el Hotel "Royal", fundado por otro comerciante de origen inglés, y los hoteles "La Bolsa" y "Alemán", que fueron abiertos por Carlos Brockow asociado con un tal Jungklaus, el primero, y por Roberto Mulach, al parecer, el segundo, en tanto que el Hotel "Génova" era de propiedad de un italiano.

Aunque varios de estos establecimientos ("Kosmos", "France", "Royal" y "Caledonia", entre otros) mantenían el giro propia y exclusivamente hotelero, pudiendo o no incluir sus anexos (restorán, cafetería y bar), otros, por lo común de inferior categoría lo combinaban con otra actividad mercantil o artesanal en las que el servicio de hospedaje era más bien un complemento. Tales los casos del Hotel "Bella Dalmacia", cuyo propietario unía su explotación a la de rubros tan disímiles como peluquería, carpintería y zapatería; del Hotel "Universal", con carnicería y del Hotel "Génova", que era publicitado como almacén y hotel. Más frecuente fue entonces y lo sería en el porvenir que la doble explotación comercial fuera más afín entre sí, combinándose la hotelería con los anexos mencionados o inclusive con el de pastelería.

En su avisaje de promoción estos establecimientos ponderaban la atención esmerada a los pasajeros, más si era "por los propietarios", la disponibilidad de buenas piezas amobladas e independientes, de una sala de baño interior y de buenos comedores, con menús variados y provisión de licores de buena clase, y también disponibilidad de pesebreras cómodas, de forraje y de potreros o patios para cabalgaduras, en fin.

Más allá de la oferta, la calidad se establecía por la privacidad de que podían disfrutar los clientes, por la confortabilidad que derivaba de la disponibilidad de calefacción y la comodidad del mobiliario, e inclusive la de haber cuarto de baño, aunque este particular servicio fue durante muchos años de uso común, en el estilo propio de la época.

En los establecimientos de categoría inferior las comodidades dejaban que desear, pues no siempre disponían de calefacción suficiente y las habitaciones eran compartidas por dos o tres personas que no 
TABLA 1. Establecimientos de hospedaje en Magallanes 1894-1952

\begin{tabular}{|c|c|c|c|}
\hline Año & Hoteles & Pensiones o Residenciales & Total \\
\hline 1894 & $6^{*}$ & $2^{*}$ & $8^{*}$ \\
\hline 1908 & $40^{*}$ & $241^{*}$ & $281^{*}$ \\
\hline 1914 & $50^{*}$ & 256 & $306^{*}$ \\
\hline 1942 & $35^{*}$ & 12 & $47^{*}$ \\
\hline 1952 & 28 & $9^{*}$ & $37^{*}$ \\
\hline
\end{tabular}

*Cantidad mínima

Fuente: Roles de Avalúos 1909 y 1914, y Guías Telefónicas para 1942 y 1952.

TABLA 2. Población de Magallanes 1895-1920*

\begin{tabular}{|c|c|c|}
\hline 1895 & 5.170 hbs. & $(3.227$ hbs. Urbanos 1.943 hbs. Rurales) \\
\hline 1906 & 13.309 hbs. & $(10.103$ hbs. Urbanos 3.206 hbs. Rurales) \\
\hline 1907 & 17.330 hbs. & $(12.699$ hbs. Urbanos 4.631 hbs. Rurales) \\
\hline 1920 & 28.960 hbs. & (23.091 hbs. Urbanos 5.869 hbs. Rurales) \\
\hline
\end{tabular}

*Fuente: Censos Nacionales de Población años 1895, 1907 y 1920; Censo Municipal Territorio de Magallanes año 1906.

se conocían entre sí. Es seguro que en estos casos la higiene también fuera algo precaria, aspecto este como aquéllos posiblemente tolerados o aceptados como cosa normal por una clientela poco exigente, que valoraba más, por regla general, un servicio de comida abundante y bueno, además de barato.

A partir de la primera década del siglo XX en que se inició el período de esplendor hotelero, que se extendió hasta aproximadamente 1920, funcionaron alrededor de sesenta hoteles propiamente tales, pero además lo hicieron hasta tres centenares de establecimientos de categoría inferior (residenciales o pensiones) que pagaban patentes de segunda o tercera clases, de acuerdo con los antecedentes contenidos en los roles municipales para los años 1909 y $1914^{9}$, sin considerarse los servicios de alojamiento y mesa prestados en casas de familia al margen de todo control municipal, situación de frecuente ocurrencia a lo largo de todo el período histórico en consideración (Tabla 1 y Apéndice).

La situación que se daba en los otros dos centros urbanizados del Territorio, Porvenir y Puerto Natales, era semejante aunque, es claro, en la correspondiente proporción que derivaba de su escasa población, pues cada uno de ellos contaba con alrededor de un millar

9 Exactamente 279 patentes en 1908 (7 hoteles de primera clase, 26 de segunda y 246 de tercera), L. Navarro, Censo Jeneral del Territorio de Magallanes, Punta Arenas 1908, y 306 patentes (19 hoteles de primera clase, 19 hoteles de segunda clase y 268 de tercera clase) en 1914, según el Rol de Avalúos Urbano y Rural del Territorio de Magallanes Año 1914. de habitantes, en tanto que su actividad económica era sustancialmente menor o mínima.

Aunque no debe excluirse la posibilidad del funcionamiento anterior de alguna casa del género, la primera referencia obtenida para Porvenir data de setiembre de 1904, época en que Georg Kaiser abrió el Hotel "Alemán", al que siguió años después el "Chile" de Miguel Radonich. Hacia fines de 1903 el francés Alcide Laforest estableció en la vecindad del chorrillo Natalis un almacén con hotel anexo que debe ser tenido como el origen del subsiguiente caserío que en 1911 fue fundado oficialmente con el nombre de Puerto Natales. En el año 1904 el empresario Rodolfo Stubenrauch que poseía importantes intereses económicos en ese distrito abrió un segundo establecimiento en el lugar. Para 1913 ya funcionaban en Porvenir 18 establecimientos del género que pagaban patente de tercera clase (hotel con restorán), la mayoría de los cuales, si no la totalidad, debía datar de la segunda mitad de la década precedente, época en que se registró el auge de la minería aurífera mecanizada, fenómeno económico que generó la afluencia de forasteros a la costa fueguina del estrecho de Magallanes. En ese mismo tiempo Puerto Natales tenía una decena de hoteles y residenciales.

La explicación para ese sorprendente, casi explosivo crecimiento de establecimientos de hospedaje se tiene en el notorio aumento poblacional registrado en Magallanes durante el período comprendido entre 1895 y 1920 (Tabla 2).

De las cifras dadas puede advertirse que la población territorial se triplicó y más entre 1895 y 
1907 (235,2\%) y casi se sextuplicó (460\%) para 1920, aumento más notorio aun en el ámbito urbano, pues aquí se cuadruplicó en el primer lapso y más que se sextuplicó en el cuarto de siglo considerado. En números absolutos el incremento fue de 12.160 personas entre 1895 y 1907 (9.472 personas en centros urbanizados) y de 23.790 entre 1895 y 1920 (19.864 personas en centros urbanizados).

El origen de este crecimiento estuvo principalmente en la copiosa inmigración libre, mayormente desde Europa, que se registró durante el período de que se trata. Este fenómeno registró mayor dinamismo entre los últimos años del siglo XIX y 1914, lo que permite entender que había entonces una gran población flotante que requería imperiosamente de alojamiento y comida (Martinic 1992b).

La respuesta a esta urgente demanda social se dio con la oferta consiguiente de servicios, esto es, con la apertura y proliferación de sitios de hospedaje de diferente clase. El fenómeno fue particularmente notorio en Punta Arenas donde por razón de su gravitante población se concentró sobre el $90 \%$ de la hotelería del Territorio durante el período.

El auge del negocio hotelero sugirió a algunos comerciantes y estancieros que disponían de recursos financieros la posibilidad de instalar un establecimiento de gran categoría en Punta Arenas, acorde con las exigencias del confort, en todo semejante a los hoteles de las grandes capitales. Para ello los interesados acordaron constituir una entidad anónima denominada Sociedad Industrial Grand Hotel, lo que se hizo por escritura de 8 de marzo de 1907, asumiendo la dirección gerencial de la misma Conrado Holtz, empresario con experiencia en el ramo. Sin embargo de un auspicioso comienzo la iniciativa no marchó como era de esperar por falta de suficiente capital y la sociedad acabó disolviéndose un par de años después. Un cuarto de siglo más tarde, en 1934, la idea sería recogida como una posible inversión de la Sociedad Anónima Ganadera y Comercial Menéndez Behety, pero tampoco llegaría a concretarse.

Económicamente considerada, la actividad debe ser estimada como de importancia, no obstante la imposibilidad de su cuantificación por ausencia de datos, con el compromiso de un capital que debió ser de monto apreciable. Basta calcular lo que la misma hubo de significar en inversiones inmobiliarias (edificación, ampliaciones y demás), en dotación de muebles y otros elementos, en el abastecimiento regular de provisiones y otros efectos requeridos para una adecuada instalación y funcionamiento, del mismo modo que en la ocupación de mano de obra bien en forma directa (mozos, mucamas, cocineros, etc.) o en forma indirecta por el movimiento comercial generado por la actividad hotelera. Insistimos, aunque indeterminable la misma debió ser significativa en el conjunto de la economía territorial, lo que justifica su consideración.

En cuanto a su ubicación, casi la totalidad de los hoteles propiamente tales se hallaban en la zona portuaria de Punta Arenas, en un radio de no más de tres cuadras desde la salida del muelle de pasajeros, en el inicio oriente de la calle Coquimbo (actual Errázuriz), siendo más abundantes en esta vía y en la de Concepción (Roca) y en la de Llanquihue (O'Higgins); ello, naturalmente para la mejor comodidad de los pasajeros que así no debían recorrer gran distancia. Inclusive, había hoteles como el "Kosmos", que estaba situado junto a la misma antigua línea de playa en la calle Coquimbo, o como el "Sea Harbour View" que se ubicaba en la salida misma de aquel muelle, según se aprecia en una postal fotográfica de 1908. La excepción en cuanto a situación la hacía el Hotel "Caledonia", que se hallaba sobre la calle Atacama, en el acceso norte de la ciudad, por tanto al paso de cuantos procedían desde el interior del Territorio.

Respecto de la nacionalidad de los propietarios y siguiendo el patrón propio para la actividad económica de la época en Magallanes, había un notorio predominio de los europeos. En efecto, de la consideración de los apellidos de los enrolados para el pago de las correspondientes patentes municipales, puede generalizarse que aquéllos se situaban por sobre los chilenos (grupo en el que por fuerza han debido incluirse los españoles), en la proporción de un $70 \%$ versus $30 \%$. Ahora bien, entre los europeos era notoria la presencia de croatas, del orden de un 65\%, seguidos por los italianos, británicos, alemanes, franceses y otros, en ese orden. Pero, al considerarse la categoría de los establecimientos, la propiedad europea era abrumadora en los de primera clase y dentro de la misma era significativa la participación de británicos y alemanes, seguidos de franceses, croatas e italianos.

Pero también la hotelería debe ser valorizada desde el punto de vista social, pues ha de conve- 
nirse en su trascendencia en la vida de relación de comunidades aisladas del mundo, como eran las del Magallanes de otrora. En sus bares, cafeterías y comedores confluyeron pasajeros venidos de otras partes con la gente del Territorio, y allí se intercambiaron noticias, se establecieron amistades, se plantearon y acordaron negocios, proyectos y propuestas de diferente género $\mathrm{y}$, del modo como hubiera sido hubo de darse una relación fructífera, mucho más en el ámbito rural donde su significación social fue todavía mayor.

Los hoteles de Punta Arenas, los de mayor categoría, fueron teatro de más de algún suceso de relevancia ocasional dada la celebridad de algunos huéspedes en ellos alojados. Así el "Kosmos", tradicionalmente el hotel preferido de los alemanes, no obstante haber otros establecimientos del género que pertenecían a gente de esa nacionalidad ("La Bolsa", "Kap Horn", "Alemán", "Stadt Hamburg"), alojó a los más conspicuos de los visitantes germanos, diplomáticos, comerciantes y empresarios; pero también fue escenario de sucesos singulares, como el ocurrido el 5 de abril de 1901 cuando en su patio se realizó el remate de la caballada que había sido utilizada en la expedición dirigida por el periodista inglés Hesketh Prichard, del diario Dayly Mirror de Londres, que había recorrido la Patagonia andina oriental jen la búsqueda de un milodón vivo! ${ }^{10}$. Este hotel se vio excepcionalmente afectado por la pérdida de clientela luego del comienzo de la Gran Guerra Europea (Primera Guerra Mundial) por su identificación con los intereses alemanes. Fue entonces que su propietario Carlos Brockow lo vendió al francés Julio Biget, quien ipso facto mudó su denominación, de "Kosmos" a "Cosmos", como se le conocería a partir de entonces.

El "Hotel de France", como puede suponerse, a más de pertenecer a y ser regentado por franceses, fue el lugar habitual de hospedaje para todos los compatriotas que arribaron a las playas puntarenenses y, en general para la gente de habla francesa. De esa manera, allí se alojó el grupo expedicionario polar internacional de 1897 dirigido por el Dr. Adrien de Gerlache, eminente científico

10 Cfr. del autor 'La Cueva del Milodón: Historia de los hallazgos y otros sucesos. Relación de los estudios realizados a lo largo de un siglo (1895-1995)'. Anales del Instituto de la Patagonia, Serie Ciencias Humanas, volumen 24 (Punta Arenas, 1996). belga, y en el que entre otros figuraba el sueco Roald Amundsen, futuro conquistador del Polo Sur. Allí también, en sus comedores, la colonia francesa de Magallanes homenajeó en 1910 al Dr. Jean B. Charcot, otro famoso explorador polar, a su regreso de la Antártica.

El Hotel "Royal", fue por definición el hotel de los británicos. Él en cierto modo era la residencia habitual de los estancieros y administradores de estancias cuando venían desde el interior patagónico y de la Tierra del Fuego, o desde suelo argentino, por alguna necesidad. Rivalizaba en calidad con el "Kosmos", de allí que compartieron lo más selecto de las visitas arribadas a la capital territorial. Allí, entre tantos, alojaron el célebre explorador polar capitán Ernest Shackleton, tras su memorable y heroico periplo por aguas polares y meridionales en 1916, junto con sus compañeros tras el rescate de la isla Elefante por la escampavía nacional Yelcho, comandada por el piloto Luis Pardo.

Fundada la filial local del Rotary International, sus miembros eligieron este hotel como la sede de sus reuniones semanales, lo que ocurrió hasta fines de los años de 1920 cuando un incendio destruyó por completo al establecimiento. A partir de entonces esa sede institucional pasó al Hotel "Cosmos" en donde se mantuvo hasta su cierre pasado 1950.

Si los más acreditados hoteles de Punta Arenas se esmeraban en ofrecer un servicio de la máxima calidad, buenas habitaciones, ambiente confortable, la mejor mesa y la higiene más exigente, no ocurría lo mismo con los establecimientos de menor categoría donde todas aquellas características solían darse, si es que se daban, en grado menor. Las residenciales o pensiones ofrecían por lo común al pasajero las mismas comodidades de que disponía la familia del propietario.

\section{a.2 Período $1921-1950$}

Condicionada como se hallaba por el fenómeno inmigratorio, cuando éste bajó notoriamente su intensidad durante el curso de la postguerra mundial y primeros años de la década de 1920, en un contexto generalizado de cambios de diverso orden que afectaron el curso de la vida y la economía del Territorio de Magallanes, la hotelería se resintió visiblemente, en especial la urbana -la de Punta Arenas-, que fue la más afectada. La mis- 
ma dejó de contar para su funcionamiento con el aporte de clientela procedente del exterior, ahora muy disminuida; y también por otra razón propia del ordenamiento social. Ocurría que en la natural evolución de una comunidad la población flotante y de paso de tiempo antes, o desapareció o se restringió paulatinamente, para ser reemplazada por la incorporación plena en el cuerpo social, ya con estabilidad ocupacional, bien por la constitución de familias, bien por la residencia permanente en caso de soltería y, en ambas situaciones por la adquisición o arrendamiento de viviendas, lo que significó dejar de usar los alojamientos de antaño. Otro hecho concurrente fue el registrado en la crianza ovejera a partir de 1920 y que dice relación con su consolidación como actividad económica y por tanto con dotaciones laborales estables de año redondo y numéricamente acotadas en el caso de las faenas estacionales. Todas estas situaciones, al interactuar entre sí contribuyeron a la progresiva estabilización numérica de la población rural hacia la cuarta década del siglo XX.

En ese proceso complejo la hotelería o, si se prefiere, el servicio de hospedaje, fue perdiendo importancia de manera rápida, al punto de que en la década de 1930 su estado poco recordaba al tiempo de auge de veinte años antes, situación más notoria durante los años de 1940. Definitivamente el tiempo histórico de la hotelería como se la había visto antaño, había pasado (Tabla 1).

En el transcurso del período de decadencia del negocio hotelero de que se trata, fueron numerosos los establecimientos que se cerraron y únicamente subsistieron aquellos que habían logrado acreditarse por su calidad, los que bastaron para la atención de una demanda disminuida de hospedaje. Entre ellos estuvo el Hotel "Cosmos", cuya preeminencia pasó a ser indiscutida tras el siniestro que destruyó al Hotel "Royal" a fines de los años de 1920, y también el "de France" y el "Imperial", este que fue adquirido posteriormente por el empresario Luis Travini, mutando su nombre al de "Savoy", y consiguió mantenerse como buen establecimiento en discreto segundo plano hasta superar el período histórico en consideración ${ }^{11}$.

Pero, sin duda alguna, fue el primero el que para la historia se llevaría las palmas de la fama por

11 De hecho continúa operando hasta el presente. su reconocida calidad y su jerarquía. Tal fue así que en manos de la firma Juan Toth \& Cía., cuyo socio principal era un hombre de reconocida experiencia en el ramo, se fue ampliando y modernizando para responder a las exigencias de su selecta clientela aunque, claro está, sin perder su grato estilo tradicional. Para 1933 disponía de sesenta habitaciones con baño, de suyo algo inusual en la época y el medio; $e$ inclusive había debido construirse un edificio de material sólido para el funcionamiento del anexo, a diferencia de la construcción original que lo era de madera, característica que conservaba el ambiente atractivo y confortable de la época pasada.

En una edición del diario El Mercurio de Santiago, de 12 de setiembre de 1933, dedicada a la Provincia de Magallanes, se contenía una extensa referencia sobre el establecimiento:

Al llegar uno a Magallanes [Punta Arenas], y por muy bien informado que [se] esté de su grado de adelanto y desarrollo, no se imagina que pueda existir en la ciudad un hotel tan espléndido como el COSMOS. Y, en realidad, es una sorpresa el sentirse acogido en un ambiente elegante y confortable como el que éste ofrece.

El arreglo, que es una manifestación del buen gusto de sus propietarios, hace recordar los mejores hoteles de gran categoría que hayamos visitado en los principales países. El gran hall central, cuya fotografía insertamos en estas mismas columnas, es un amplio recinto arreglado con gusto refinado y mirando siempre por el confort de las personas que allí deberán permanecer. Una gran estufa a leña de moderno y elegante corte, siempre encendida, comunica a la sala una agradable temperatura que le da de inmediato un grato ambiente hogareño, completado por el cómodo moblaje de amplios y muelles sillones que invitan al reposo y a la tranquilidad.

[...] El HOTEL COSMOS cuenta con más de 60 habitaciones confortables y hermosamente amobladas, siempre a disposición de los pasajeros. Todas ellas poseen calefacción y están servidas constantemente por personal competente contratado personalmente por el señor Toth, quien exige condiciones y conocimientos especiales de atención de público.

[...] El comedor del hotel es, como el hall, recinto de un aspecto realmente hermoso y acogedor. El señor Toth ha comprendido que el comedor de un hotel es tal vez el sitio en que preferentemente 
debe atenderse a la comodidad de los pasajeros. En el Hotel Cosmos el comedor es espacioso $y$ adornado en forma sobria pero elegante. Se siente uno en él como en cualquiera de los grandes hoteles de las principales capitales, donde se recoge la sensación de tener a su alcance todas las comodidades deseables y el mejor servicio que sea posible obtener.

[...] El ambiente de este hotel es sin duda distinguido, de manera que no es raro encontrar en él lo más representativo y selecto de la sociedad magallánica, así como los más ilustres viajeros que van a la bella ciudad austral en visita de negocios, salud o placer.

Y así por el estilo; es una relación periodística que no por ditirámbica deja de ajustarse a lo que en verdad era una realidad conocida.

Ratifica esta apreciación la descripción que sobre este hotel hiciera el viajero A. F. Tschiffely, quien se alojó en él por ese mismo tiempo, al llegar a Punta Arenas en uno de los recorridos que le ganarían fama:

[...] continué hasta el Hotel Cosmos, que es el centro del universo para los ciudadanos de Punta Arenas, para no mencionar los criadores de ovejas que de tanto en tanto entran retumbando en él, haciendo los más originales esfuerzos por parecer la encarnación de Creso.

El Hotel Cosmos, de dos plantas y bastante cómodo, es conocido por todos los viajeros que han visitado el Estrecho. Muy de tanto en tanto un buque cargado de turistas, en su camino alrededor del mundo, toca tierra en Punta Arenas, lo cual quiere decir que algunos pasajeros bajan para cambiar de dieta. Asimismo, las expediciones Antárticas tienen sus cuarteles allí antes de saltar hacia las regiones heladas cercanas al Polo Sur. En lo que se refiere a la intelligentsia local, el Hotel Cosmos es el Palacio de Buckingham, el Ritz, el Waldorf Astoria y el Forum Romanorum, todos en uno; un lugar de reunión social sin el cual el universo dejaría de existir, escribió Tschiffely redondeando el irónico bosquejo caracterizador del establecimiento ${ }^{12}$.

12 Por este camino hacia el sur. Un viaje a través de la Patagonia y Tierra del Fuego (Editorial "El Jagüel", Buenos Aires, 1998), págs. 232 y 234. La edición original del libro se publicó en inglés, en Londres, 1945.
No obstante la restricción del negocio durante el lapso, así como se cerraban establecimientos, solían abrirse, aunque escasos, otros nuevos. Algunos como el Hotel "Hispano Americano", de buena calidad si bien de vigencia relativamente breve y el Hotel "Cervantes", uno y otro de los años 30. Este último pertenecía y era manejado por propietarios de nacionalidad croata y situado en una categoría secundaria, consiguió ganar acreditada fama como hotel familiar, tradicionalmente preferido por los viajeros fueguinos de aquel origen, lo que le daría una particularidad caracterizadora, según lo comprobaría el viajero argentino Jerónimo Gómez Izquierdo.

Al mismo debemos una referencia sobre el Hotel "Nacional" en que alojara en Porvenir, camino de Punta Arenas, y que merece ser transcrita por cuanto entrega un retrato caracterizador para todos los hoteles de segundo orden de la época de los poblados pequeños en uno y otro lado de la frontera internacional:

[...] Me instalaron en la habitación 11; tiene ancho ventanal con blancas cortinillas; pieza chica, paredes de madera, como en casi todos los hoteles patagónicos; madera y chapas, tabiques forrados de papel; pensaba en la gran suerte que tienen esos pueblos fueguinos y patagónicos, no he oído que haya incendios, pues de ocurrir esa desgracia, con los vientos violentísimos que soplan, no quedaría ni rastro de los poblados. Desde el ancho ventanal que da frente a la bahía, dominaba el panorama; veía los cerros que rodean a Porvenir, podía extasiarme contemplando el azul intenso de las aguas del Estrecho que entran allí llenando el espacio de la bahía ovalada, alargada en forma de bolsa a lo largo de cuya orilla está la avenida principal, con sus casas de cinc y madera, de formas caprichosas, mirando al agua y todo el pueblo sembrado en la pendiente hacia la cima de las colinas que rodean el paraje, lindo de verdad, que miraba desde el ancho ventanal; entraba la luz abundante, escribía sobre la única mesa, la mesita de noche y cuando me cansaba lo hacía en la cantina del hotel en cuyas mesas se estaba más cómodo, si no fuera por el entrar y salir, las conversaciones y el ruido; durante mi largo viaje me era bastante difícil escribir, en ningún hotel pude tener una mesa a mi gusto, excepto en Trelew, al iniciar el viaje.

Desde mi habitación oía roncar al vecino del 12 , toser mucho al del 10 y disputar a un matrimonio con dos niños del 8 y también sentía crujir 
las tablas del piso cuando bajaban las escaleras; la luz de mi cuarto se apagaba pasada la media noche, como en Río Grande, de manera que se empleaban las palmatorias y quinqués como iluminación suplementaria ${ }^{13}$.

Según corrieron los años el negocio de hospedaje, el hotelero propiamente tal, hubo de adaptarse a las situaciones que afectaron el suceder de Magallanes en lo tocante a la disminuida y crítica actividad económica general, circunstancias que fueron aventando los restos del esplendor de antaño, objeto de añoranzas y nostalgias.

Quizá los últimos momentos de bonanza para el negocio en Punta Arenas se dieron al promediar la década de 1940, época en que tuvieron ocurrencia dos sucesos de resonancia social y que dieron motivo para la llegada masiva de forasteros y por tanto de clientela para los hoteles. Estos fueron la celebración del Centenario de la Toma de Posesión del Estrecho de Magallanes por la República de Chile, con varios actos de diversa índole, los principales de los cuales contaron con la presencia del Presidente Juan Antonio Ríos (febrero de 1944); y del IX Congreso Eucarístico Nacional, que se desarrolló entre los días 6 y 10 de febrero de 1946.

En el caso particular de Porvenir, este pequeño centro fueguino mantuvo su actividad hotelera tradicional, en especial para la atención de la gente que procedía del interior rural y que tanto podía permanecer allí para atender diferentes asuntos, como aguardar la llegada de los vapores que hacían la carrera entre ese puerto y Punta Arenas. Pero ese período de bonanza fue perdiendo vigencia una vez que a contar de 1945 se estableció la comunicación aérea entre las dos orillas del estrecho de Magallanes, que sin embargo de ser tenida como manifestación de modernidad tuvo impactos negativos irreversibles en la actividad mercantil local a poco andar, incluido el servicio de hospedaje.

\section{b. La hotelería rural}

\section{b.1 Período $1880-1920$}

Aunque recorridos desde largo tiempo antes por cazadores y traficantes, y uno que otro viajero

13 Tierras Australes. La Patagonia, Tierra del Fuego (Empresa Editorial Bell, Buenos Aires, 1942), pág. 185. o explorador, los terrenos del interior continental situados al norte de la colonia de Punta Arenas comenzaron a ser poblados en forma a partir de 1880 con la ocupación paulatina de campos pastoriles y el surgimiento de pequeñas estancias. Así entonces sólo al cabo de algunos años se pudo registrar algún movimiento de personas como para justificar la apertura de establecimientos de hospedaje.

Sin embargo de ello, fuera de toda duda el primero de estos hoteles de campaña, como pasó a denominárselos, hubo de ser el que abrió el colono suizo Emilio Bays, que poblaba un pequeño campo en Cabo Negro, teniendo como antecedente el servicio ocasional de alimentación y alojamiento que había brindado hacia fines de los años de 1870.

En efecto, ya en enero de 1879 con sólo días de diferencia fueron atendidos allí por la diligente doña Micaela, esposa de Bays, el príncipe Enrique de Prusia, hijo del heredero al trono imperial de Alemania, durante una excursión de caza; y posteriormente el sargento mayor Diego Dublé Almeida, antiguo gobernador de Magallanes, de paso para el estuario de Santa Cruz en misión especial.

Otros lugares en que pronto se abrieron hoteles-almacenes, razón por la que la gente de campo dio en llamarlos "boliches", fueron los parajes de Chabunco y Cabeza del Mar, por los que transcurría la huella tropera que arrancaba desde Punta Arenas con destino a las pampas del centro y del oriente, y a los sectores boscosos de la precordillera. Aunque se desconoce con certidumbre la fecha de su apertura, se sabe que en los primeros años de la década de 1890 había hoteles rurales en Tres Puentes, uno o dos; en Río Seco, como en Chabunco, paraje donde el mencionado Bays asociado con un tal Lecocq estableció un hotel en 1895; en Cabeza del Mar, encrucijada de rutas, donde desde 1890 a lo menos funcionaba un establecimiento de propiedad del escocés Alec Mac Donald; en Río Verde, donde había dos hoteles junto al canal Fitz Roy, en el punto de cruce a la isla Riesco; y en Pozo de la Reina, en la bifurcación de sendas que conducían al oriente (San Gregorio, Punta Delgada, Posesión) y al noreste, a Dinamarquero, Ciaike y Argentina. Aquí el propietario era Henry Meade, antiguo soldado del bando de la Confederación en la guerra civil norteamericana. Más hacia el interior, en el sector de Laguna Romero, estaba el hotel homónimo, propiedad del inglés Charles Finger. 
Este establecimiento al parecer fue abierto a mediados de 1894, a juzgar por texto del siguiente aviso publicado en el diario El Magallanes de 9 de setiembre de ese año, en castellano y en inglés:

\section{A LOS MINEROS Y HOMBRES DE CAMPO}

Pongo en conocimiento de los ovejeros, hombres de campo y mineros que trabajan en las cordilleras [buscadores de oro] que he establecido un almacén cerca de la Laguna Romero, al lado del camino que conduce á Gallegos. Todas las mercaderías son de primera clase y encontrarán un completo surtido, siendo los precios muy módicos. Pago al contado violento.

Finger \& Ca.

Insistimos en que no obstante promoverse como almacenes y ser conocidos como boliches, estos establecimientos tenían un objetivo mercantil mixto: venta de licores, provisiones y artículos diversos, y servicio de comida y alojamiento.

Hasta 1900 fueron abriéndose otros hoteles: en el sector oriental de la laguna Blanca (La Leona), junto a la senda que conducía al valle medio del río Gallegos; también en otro lugar indeterminado de la periferia lacustre, quizá en el cabezo sur, así como en Morro Chico, donde había dos o tres establecimientos, uno de propiedad de un tal Kraft, alemán, muy frecuentado al parecer por los aónikenk de la reserva situada en el valle del río Zurdo, y otro de Paul Lemaitre, estanciero. En Última Esperanza se instalaron hoteles en Puerto Prat y Puerto Cóndor en los años finales del siglo XIX, y más tarde en Tres Pasos, camino del norte entre la costa del fiordo de aquel nombre y Cerro Castillo.

En la zona sur de Punta Arenas, desde temprana época había hoteles en los parajes de Río de los Ciervos y en Leñadura, zonas litorales de actividad agrícola y ganadera, y también en Tres Brazos, centro de producción industrial maderera, y, por fin en Pampa Guayrabo, algo más al sur.

Tales instalaciones eran posibles desde que todos los terrenos eran fiscales y podían ser ocupados por quien quisiera, con la debida autorización de la gobernación del Territorio, bien como tenedores precarios, y las mismas eran entendidas como parte de la mayor y variada actividad que exigía el proceso colonizador en diferentes sectores de la zona oriental del territorio magallánico. No era éste, sin embargo, el caso de la isla grande de Tierra del Fuego, en donde se habían hecho cuatro grandes concesiones fundiarias que para 1910 devendrían únicamente dos, entre ambas la muy importante que detentaba la poderosa Sociedad Explotadora de Tierra del Fuego. Esta entidad desde un principio se preocupó que por sus vastas posesiones el tránsito de personas correspondiera exclusivamente al de sus propias necesidades operativas, por lo que cualquier extraño era mal visto y alejado de los campos que explotaba esa compañía.

Así entonces, en la isla grande fueguina los primeros hoteles surgieron en el distrito aurífero del noroccidente, en las vertientes de la sierra Boquerón que aunque se hallaban comprendidos en las concesiones de la Sociedad Wehrhahn, Hobbs y Cía. (después Sociedad Ganadera Gente Grande), y de la Sociedad Explotadora de Tierra del Fuego, las circunstancias de hallarse ocupados por mineros y de ser terrenos de baja calidad para el uso pastoril los había dejado al margen de esta explotación económica. De allí que fuera tolerada la instalación de hoteles en diferentes lugares del sector. Los primeros de estos establecimientos fueron los denominados Hotel "Casa de Lata" y Hotel "Baquedano", pero después, pasado $1900 \mathrm{al}$ parecer, se abrieron otros en el asiento minero de Río del Oro, en Discordia y Los Morros. Con posterioridad, hacia 1915-16, una vez que a la Sociedad Explotadora le fue renovado el arrendamiento de los campos que ocupaba, debió restituir al Fisco una parte de ellos, precisamente los que correspondían al sector de la sierra Boquerón. Allí se inició entonces la recolonización ovejera en fracciones medianas y pequeñas de campos, abriéndose así la posibilidad a la iniciativa económica de terceros. En ese contexto comprensivo surgió un nuevo hotel, el de Bahía Inútil, inmediato a Puerto Nuevo y junto al camino tropero que unía Porvenir con la parte central de la isla y la frontera internacional (San Sebastián), y justo en el límite que a contar de la renovación del arrendamiento separaba los antiguos y actuales campos de la Sociedad Explotadora.

Entrado el siglo XX, el número de hoteles de campaña prosiguió aumentando. En Patagonia se instalaron otros más en Tres Puentes, en Río Seco, Chabunco, San Francisco, Otway, Cruce Fabres, Cruceros, Carpa Manzano, Dinamarquero y Ciaike. 
Esta proliferación de establecimientos hoteleros de campo fue cediendo en ímpetu y de modo notorio después que entre 1903 y 1906 se realizaron los remates de las tierras fiscales de la Patagonia, proceso del que como es sabido derivó el fenómeno del latifundio por la concentración de los terrenos pastoriles en pocas manos (Martinic 1992a). Los nuevos propietarios impusieron la privacidad de sus dominios y no fueron proclives a la instalación de cuantos pretendían explotar el negocio hotelero, pues se veía en los establecimientos del género a focos eventuales de perjuicio para sus intereses, desde que en casos de abigeato algunos de esos empresarios solían aparecer como partícipes o como reducidores. También se miraba con recelo la venta de bebidas alcohólicas, a veces excesiva, que se hacía a la gente de campo, de la que derivaban o podían derivar hechos luctuosos, todo lo cual de algún modo perturbaba o podía perturbar el ordenamiento rural que se pretendía establecer. Así, por otra parte y por parecidas razones desaparecieron algunos antiguos hoteles de campaña, por la vía simple de no renovárseles a los propietarios el arrendamiento de las pequeñas unidades prediales (parcelas o hijuelas) donde aquéllos se hallaban instalados.

El Rol Municipal de Avalúos para el año 1914 registraba 46 patentes de tercera clase, correspondientes a otros tantos establecimientos desperdigados por los distritos de Magallanes centro-oriental, península de Brunswick, Última Esperanza y Tierra del Fuego. Había sectores en los que funcionaban varios de ellos. Tales Río de los Ciervos (6), Leñadura (3), Tres Brazos (3); Tres Puentes (3), Río Seco (5), y Chabunco, Río Verde y Morro Chico, dos en cada localidad.

Tocante a la propiedad, prácticamente la totalidad de ellos correspondió a europeos, británicos, alemanes, franceses y otros en un primer tiempo (antes de 1900), a los que posteriormente y hasta el final del período se sumaron croatas que pasaron a hacer la mayoría de los propietarios. Los chilenos virtualmente no participaron en este negocio y la gran excepción la hizo Rogelio Figueroa, propietario del Hotel "Tres Pasos", en Última Esperanza.

Una descripción caracterizadora para la generalidad de estos establecimientos hacia fines de la década de 1910 la dejó el capitán del ejército Carlos Fuentes Rabé al hacer mención al Hotel "Casa de Lata", tras un recorrido por el interior de la isla grande de Tierra del Fuego, realizado en 1918:
El Hotel constituye un depósito donde no falta nada y donde se reune todo lo indispensable para la vida del campo; es una especie de almacen de menestras, tienda de trapos, abarrotes, merceria, chancheria, cigarreria, zapateria, etc., etc.

Multitud de botellas de todos tipos y tamaños ocupan el mayor espacio del negocio; son ellas las que tienen mas venta y por eso se las mantiene a la mano. Una pieza provista de algunas mesas, indica el comedor y sala de reunion. El propietario del establecimiento espresa que mayores comodidades no son necesarias en aquella rejion; "Casa de Lata", está mui próximo de Porvenir y son mui raras las ocasiones en que los pasajeros se ven obligados a pernoctar en el Hotel; su negocio constituye tan solo un punto de descanso y un centro de aprovisionamiento para los transeuntes rezagados ${ }^{14}$.

La observación del propietario respecto de las comodidades que podían brindarse al pasajero debieron ser compartidas por otros propietarios de esa época y la posterior. Vale ejemplificar con la mención que hizo en su diario de viaje el arqueólogo norteamericano Junius B. Bird cuando arribó a la caleta de Río Verde en 1935, finalizando así un largo recorrido marítimo por los canales patagónicos acompañado por su esposa en el cúter Hesperus: A través del canal fuimos en un bote a motor hacia el pequeño hotel [Río Verde]; era limpio y agradable y decidimos quedarnos allí. [...] Hubo un gran revuelo en el hotel cuando pedimos un baño; finalmente obtuvimos una gran tina de madera, gran cantidad de agua caliente $^{15}$

Considerada desde el punto de vista social, la hotelería rural del antiguo Magallanes (como en general la de toda la Patagonia), fue una actividad que excedió la función esencial propiamente económica. En efecto, para la gente de campo, máxime si trabajadores sin rango (peones, gañanes, ovejeros, puesteros, arrieros), un hotel de campaña era mucho más que el lugar en donde se podía concurrir a gastar en consumo de bebidas -a veces de una sentada- todo el salario acumulado en meses de

14 Tierra del Fuego, (Valdivia, 1923), tomo II, pág. 138.

15 Viajes y Arqueología en Chile Austral (Ediciones de la Universidad de Magallanes, Punta Arenas, 1993), pág. 30 . 
trabajo, o bien tomarlo al fiado, con la seguridad de pago posterior; o el sitio en que se podían adquirir los artículos más variados de uso corriente que podían necesitar, desde pañuelos hasta hilo de coser, pasando por ropa interior, artículos de tocador y fruslerías, tabaco y yerba mate, conservas comestibles, etc., etc.

Allí además, se tenía la posibilidad de encontrar a otra gente, ajena al campo, de diferente clase y procedencia, alternar con ella o simplemente escucharla hablar sobre tantas cosas distintas a las propias de la rutina cotidiana. Todo interesaba al cliente ocasional, más aún si era del campo adentro, cansado de aburrimiento al cabo de largo tiempo de ver siempre las mismas caras o casi sin ver ninguna, como era el caso de quienes vivían aislados en puestos de estancia. Ahí se podían llevar las contadas novedades comunes de la rutina del quehacer ganadero ovino y recoger todo lo que se podía del "mundo ajeno" cercano o distante, de lo que se encargaba el patrón o mesonero que actuaba de transmisor de noticias ad hoc.

Para los que eran de poca conversación, que los había bastantes, lo usual en muchos casos podía ser sólo el compartir en silencio, escuchando y a veces con mucha atención, en tanto se consumía un interminable trago. Para quien vivía agobiado por la soledad, por necesidad laboral, un hotel de campaña que de suyo era un lugar solitario y aislado devenía por la fuerza del cambio del ambiente todo un mundo siempre novedoso.

El hotelero, o su mujer o alguna hija mayor, si las tenía, podían prestar un servicio particular a los clientes rústicos: el de leer las cartas que habían escrito parientes o seres queridos, cuando el receptor era analfabeto, y también el de escribir las respuestas, con el encargo adicional de despachar las cartas con el primer correo que pasara.

Los hoteles o boliches de campaña fueron así lugar de consumos, de alojamiento, de venta y suministros varios, de compra de pieles silvestres y de oro en polvo, cuando procedía, y aun de pequeñas partidas de lana "de campo" y cueros, cuando las mismas eran bien habidas, aunque no faltaron ocasiones para las que en algunos casos los hoteleros adquirieran otras que no lo eran tanto... Pero también sirvieron como agencias de encargos, bancos ad hoc o casas de préstamo, funciones significativas e inapreciables en un territorio enorme y apenas poblado con tres centros urbanizados tradicionales.

Así era la vida de la antigua campaña patagónica. Pero, vale reiterarlo, la principal función de los hoteles rurales históricamente considerada fue la de servir de lugar de relación social, aspecto más valorizado todavía cuando se vivía en la soledad y el aislamiento.

El acceso a una fuente excepcional de información, como es el caso del Libro de Cuentas perteneciente al Hotel "Tres Pasos", que comprende el lapso 1905-07, nos ha dado la posibilidad de entender mejor la forma de manejo cotidiano en un establecimiento del ramo. De partida, en lo referido a la variedad de servicios que podía prestar un hotel de campo en una zona de neta frontera colonizadora como era el entonces remoto y cuasi aislado distrito de Última Esperanza en esa temprana época del siglo XX.

Desde luego el alojamiento, la comida y la bebida, razones naturales de un negocio hotelero; pero también venta de provisiones diversas, de ropa, calzado y aun medicamentos simples; de tabaco en todas sus formas (cigarros, cigarrillos, habanos, hojas); forraje para cabalgaduras y bueyes de tropa, y talaje para ganado en arreo. También se atendían comisiones o encargos de administración de dinero, lo que da fe del grado de confianza que inspiraba el hotelero, y se hacían préstamos limitados; se atendía la recepción y despacho de correspondencia, del mismo modo como, aunque raramente, la suscripción de diarios de Punta Arenas y Santiago, y por fin la venta de números de rifa o lotería y las apuestas para carreras troperas, lo que por entonces era de común ocurrencia en zonas rurales. A lo mencionado es preciso añadir la compra y venta de frutos silvestres, los servicios eventuales de reparación de carruajes o de herraje, o aun el préstamo o reemplazo de caballos.

Había consumidores que pagaban sin mayor tardanza, pero otros abonaban y consumían en cuentas sin fin que podían tomar más de un año en su vigencia. Se cancelaba normalmente en dinero o con vales contra cobro en oficinas o agencias empresariales de Puerto Prat o Punta Arenas; pero asimismo se podía cancelar con trabajo personal o con especies tales como yugos, aperos, animales, en fin. Nadie se escapaba de pagar y aquellos excesivamente morosos quedaban advertidos con 
un timbre que se estampaba sobre su cuenta y que contenía la leyenda "Si no cancela la presente cuenta, no se abrirá una nueva". Valía la pena pues andar bien con el hotelero, cuyos servicios siempre eran de menester.

A juzgar por las cuentas, en aquellos tiempos pioneros se consumía que era un gusto; más que comer, se bebía: whisky, ginger ale, ginebra (Bols); cerveza blanca y negra; sidra y champaña; ron, anís, ajenjo, jerez, chicha, etc. y vino (Panquehue y Subercaseaux). El whisky, la ginebra y la cerveza, eran las bebidas más consumidas. En cuanto a precios, aquí van algunos: un buen almuerzo costaba en 1905 \$1,50; un barrilillo de ron \$2; un frasco o porrón de whisky, igual suma, y un litro de chicha, $\$ 1$; uno de vino corriente, la mitad de ese valor, $y$ embotellado (Panquehue) \$2,50 la unidad; la botella de ginebra importada $\$ 3$. Y no sólo se pagaban los consumos, sino los daños, como le ocurrió a un tal Will Ford, quien en febrero de 1905 debió pagar "platos rotos intencionalmente" según se le cargó en la respectiva cuenta.

En lo que dice a nacionalidades de cuantos andaban por o residían en esas remotas tierras precordilleranas, de sobre más de un centenar y medio de nombres mencionados en el libro, puede advertirse una abrumadora mayoría de apellidos de origen hispano, no siendo posible diferenciar con seguridad a chilenos de españoles, aunque es seguro que aquéllos predominaban. Es notoria eso sí la escasa mención de apellidos chilotes comunes hoy en día, de lo que puede inferirse que los trabajadores de tal origen, después tan abundantes en Última Esperanza, debieron arribar al territorio con posteridad a 1905-07. Son muy frecuentes en cambio los apellidos nacionales propios de la zona central del país.

Entre los extranjeros hay predominancia absoluta de británicos (ingleses, escoceses, irlandeses y otros), circunstancia que no debe llamar la atención, conocida como es la cantidad de individuos de tal procedencia entre los primeros colonizadores y trabajadores especializados de los campos patagónicos. Mucho menos comunes son los apellidos de alemanes, croatas (eslavos) y franceses. También los hay escandinavos, portugueses, uruguayos, griegos, argentinos, paraguayos e italianos.

Cosa singular es la mención de indios tehuelches entre los clientes del hotel de Figueroa.
Anotamos las denominaciones de cuatro de ellos: Francisco Blanco, el cacique o jefe del grupo que por la época tenía sus tolderías en el valle del río Vizcachas; el hijo del mismo y de igual nombre; y otros dos indígenas de nombres Teto y Parapol. He aquí una nueva constancia de la presencia de este grupo de patagones que habría de ser el postrero de esa raza que habitaría en forma permanente el territorio magallánico.

Como circunstancia pintoresca en las anotaciones está la consignación de apodos o menciones especiales para individualizar a determinados clientes, algunos de los cuales serían personajes históricos, cuando de los mismos se ignoraba la denominación propia, o aun cuando conociéndosela se deseaba reforzar una característica distintiva. Tales entre otros los casos del anónimo "Suizo del perrito Bismarck"; o Will Saunders "el Gringo Loco"; o el oriental Farías; Chamberlain "el carretero de Ferrier" (pionero fundador de la estancia "Río Paine"); o Alberto "alemán alambrador de Cerro Palique"; también José A. Durand "Pequenero", William Hanschdel "Cabeza de Cobre"; Marcos López "Luchador"; Mc Clelland "que toca la gaita"; Romero paraguayo; Albert "Turro"; "Australian Jack" y por supuesto "Milodón Chico", el ya célebre Alberto Konrad, trabajador alemán a quien se le nombraba así desde hacía años, luego de su hallazgo de los restos del prehistórico milodón en la caverna de Eberhard, en 1896, hecho que le despertaría con el tiempo una fiebre buscadora de restos paleontológicos a lo largo de las montañas precordilleranas, en la creencia segura de encontrar riquezas asociadas a los mismos.

$\mathrm{Al}$ recorrerse los nombres de los clientes con cuentas en el viejo hotel de Rogelio Figueroa, nos topamos con otros personajes del período de la colonización de Última Esperanza, tales como Orozimbo Santos, auténtico pionero poblador, quien para entonces entraba a ocupar en el agreste y distante lugar que denominaría "Pudeto"; un tal Levet, suizo de Punta Arenas, responsable del traslado de correspondencia entre la capital territorial y el distrito precordillerano; o Ángel Brunel, el honrado colono hermano de Asencio, el bandido más afamado de la Patagonia austral. También Cipriano Pedreros, que con los años sería perpetuado en una calle de Puerto Natales; Felipe Santucci, que legaría su apellido a un paraje de la costa sudoriental del lago del Toro, y Leonardo Ávila, viejo trotacaminos 
por extraviados parajes en búsqueda de inhallables filones de riqueza mineral.

Las amarillentas y manchadas hojas del Libro de Cuentas del Hotel "Tres Pasos" de los años 190507, rezuman sabor al tiempo pionero y romántico del poblamiento patagónico austral, que tan bien han pintado autores como Andreas Madsen (Bocetos de la Patagonia Vieja) y Asencio Abeijón (Memorias de un carretero patagónico).

Lo escrito prueba una vez más que en materia de fuentes de información pretérita ningún documento es desechable.

De manera excepcional, los hoteles de campo fueron o sirvieron de ocasional punto de concentración para determinados actos como la celebración de festividades patrióticas o, con más frecuencia, para la realización de "carreras troperas", circunstancias que convocaban a toda la paisanada rural del entorno y también a los indígenas, como fue el caso de los aónikenk de las tolderías existentes en la reserva del río Zurdo, y de cuya ocurrencia ha dejado sabrosa relación James Radburne, un personaje característico del tiempo viejo ${ }^{16}$.

Por fin, los hoteles pudieron servir como lugar de recreo, vacación o descanso, como se dio en uno o dos de los que funcionaron en Tres Puentes durante las décadas de 1890 y hasta 1920, para el vecindario de Punta Arenas, o para personajes selectos como fue el caso de la ilustre Gabriela Mistral, quien durante su permanencia en Punta Arenas durante 1918-19 alojó en plan de reposo anímico en el hotel "Tres Pasos" de su amigo Rogelio Figueroa. Es fama que allí tanto disfrutó del hospedaje que encontró la tranquilidad necesaria para componer algunas de sus más notables creaciones poéticas, inspiradas tal vez por la sugerencia telúrica del hermoso entorno de ese establecimiento. Como lugar de descanso sirvió en años posteriores, después de 1930, el Hotel "Los Robles", de Río Rubens, quizá el único de los hoteles del género que fue pensado por su fundador y propietario, Rafael Ovando Martínez, como un establecimiento destinado tanto al servicio de los pasajeros que circulaban por el camino entre Punta Arenas y Puerto Natales, cuanto para ser utilizado como sitio de descanso ocasional para gente de

16 En Herbert Childs, El Jimmy Bandido de la Patagonia (Ediciones de la Universidad de Magallanes, Punta Arenas, 1997). ambas localidades o para los muy escasos turistas que aparecían por aquel tiempo distante.

\section{b.2 Período $1921-1950$}

Si en el caso de la hotelería urbana las causas de su decadencia pasado 1920 ya son conocidas, el de la hotelería rural atravesó por un proceso semejante durante el treintenio siguiente, aunque por razones muy diferentes.

En efecto, mientras la movilidad por el territorio magallánico estuvo dada por el uso de la cabalgadura y los artefactos rodados a tracción animal (coches, carros de diferente clase, carretas), y la rapidez de la misma se hallaba condicionada por la precariedad de las vías, cuando y donde las había ${ }^{17}$, los hoteles de campaña situados por lo común estratégicamente en los lugares de paso, en caletas litorales, en encrucijadas de rutas, en fin, pudieron prosperar y multiplicarse. Pero tal situación fue cambiando con el correr de los años, una vez que los automotores se fueron haciendo más comunes en los campos y pasaron a desplazar a los vehículos de tiro animal, y por tanto acortando los tiempos de viaje por razón de su mayor velocidad, circulación posible además por el paulatino mejoramiento de las vías camineras. Abreviándose los tiempos, las jornadas de viaje se alargaron en distancia y tal proceso fue dejando fuera del paso a algunos establecimientos en beneficio de otros mejor situados que, a su tiempo fueron dejados de lado en la medida que los caminos mejoraban y aumentaba la fuerza y velocidad de los vehículos motorizados. Inclusive, en el caso particular de los vehículos de carga, cuando éstos ya tuvieron la potencia de tracción y la capacidad como para transportar cargas de alguna envergadura, esta circunstancia condujo al progresivo abandono del transporte marítimo a favor del terrestre, y ello

17 Debe tenerse presente que el origen de los caminos magallánicos, principalmente en Patagonia continental, estuvo en la rastrillada (huellas) de los indígenas aónikenk, por la que después pasaron cazadores, traficantes y viajeros $y$, una vez iniciada la ocupación colonizadora, por las carretas, carros y coches de los pioneros. Para entonces sus condiciones de tránsito eran por demás precarias, simples huellas o sendas en el descampado o trochas en terrenos de monte bajo. Los caminos propiamente tales, en un proceso de lentísimo mejoramiento se conocieron por lo común después de 1910 una vez que comenzó y se hizo más común el tráfico automotor. 
otra vez, en desmedro de los hoteles situados en las caletas o puertos de embarque (Puerto Prat, Puerto Cóndor, Río Verde, Tres Brazos) y aun a otros situados a la vera de las vías interiores.

De ese modo, en un proceso dominado por el adelanto mecánico los antiguos abundantes hoteles de campaña fueron desapareciendo, al punto que durante la década final del período en consideración su número en toda la Provincia de Magallanes se redujo a un tercio aproximadamente de lo que había sido en 1914, con una actividad comercial cada vez más reducida y restringida en servicios, en que el alojamiento pasó a ser cada vez más excepcional, restando como de interés únicamente el de suministro de alimentos y bebidas (restorán y bar).

Con todo, si algunos desaparecían otros nuevos, aunque pocos, se incorporaban al negocio. Tales los casos de los hoteles "Agua Fresca", al sur de Punta Arenas, abierto por José Rajcevic; el mencionado "Los Robles", en Río Rubens, que fue inaugurado en 1930 junto con la apertura del tramo final por suelo nacional del camino entre Punta Arenas y Última Esperanza; y "Alcalde Sanhueza" en la zona de San Gregorio que por tanto tiempo pareció rechazar la presencia de tales establecimientos y que fue posible igualmente durante la cuarta década del siglo XX una vez que el tráfico de automóviles internacional, entre Punta Arenas y Río Gallegos, dio importancia a una variante de la antigua senda, ahora por la zona litoral del Estrecho, Punta Delgada y Monte Aymond.

Hugo Sievers, que fuera Decano de la Facultad de Agronomía y Veterinaria de la Universidad de Chile, quien recorrió la Patagonia durante los primeros meses de 1940 y que por tal razón pudo conocer y usar de los servicios de diferentes hoteles de campo, dejó una acertada descripción de uno de ellos, el de Morro Chico, y que ilustra sobre los cambios que el transcurso del tiempo había impuesto en la actividad del género:

Al detenernos en la explanada que hay frente al Hotel Morro Chico, a las 13.30 horas, hemos recorrido ciento cincuenta kilómetros. Aquí hay parada de mediodía, y para rezagados, a toda hora. Dos omnibuses de la carrera esperan a los pasajeros que habrán de partir, muy pronto, en direcciones opuestas; se llevarán estos vehículos el correo internacional. Otros dos coches y nuestra camioneta completan el conjunto.
A muy pocos kilómetros, el camino cruza la frontera. Allende el deslinde internacional, muy cerca, está el camino que habremos de transitar el día de mañana.

Morro Chico, resulta, pues, un poblado en medio de rutas y senderos convergentes de intenso tráfico y muy socorrido; hay policía, teléfono, surtidor de nafta, ventas, ligeros auxilios, etc. El pequeño "Gran Hotel de Turismo" de Marinkovic, es limpio, tiene comodidades, buenas instalaciones sanitarias; hay bar, comedores y excelente alojamiento bien aseado. La atención nada deja que desear. Por lo demás, el tránsito principal está formado, en su inmensa mayoría, por personas ya ambientadas a la región y sus peculiaridades, por lo tanto saben, con sabiduría y comprensión de las dificultades, que las exigencias desmedidas o "turísticas" no son de estos climas ni están a tono con las circunstancias. El ocio turístico aún no ha echado raíces por estos lados: es el esfuerzo, la necesidad, la diligencia y lo útil que imponen sus exigencias sobrias e inmediatas. Es el Hotel que tiene que disponer del fogón para el mate de madrugada; la cocina siempre encendida para preparar la merienda; el mesonero de buena voluntad que debe charlar con paciencia ante el consumo calmoso de una caña; la patrona que corre presurosa ante la demanda de una visita femenina; el hombre que interrumpe su sueño ante los golpes del rezagado de medianoche que pide alojamiento ${ }^{18}$.

En Tierra del Fuego una razón parecida, esto es, el movimiento de automóviles de pasajeros entre Porvenir y Río Grande y viceversa, hizo surgir el Hotel "Cañadón", entre Caleta Josefina y San Sebastián, de propiedad del palestino Faiad Abosaleh. Los hoteles "Bahía Felipe", "Estancia Nueva" y "Punta Espora" fueron los últimos en incorporarse a la geografía vial fueguina. Los dos primeros pudieron abrirse entre 1939 y 1941 luego que la Sociedad Explotadora de Tierra del Fuego obtuviera en 1938 la renovación anticipada de parte de su vasto arrendamiento fundiario, pero con la obligación de restituir al Fisco los campos del norte de la isla grande, sobre los que pasó a desarrollarse el subsecuente proceso de la subdivisión predial y la recolonización. En tal circunstancia y como había

18 Rutas Patagónicas (Editorial Orbe, Santiago, 1948), págs. 87 y 88. 
ocurrido en 1915-16 con la devolución de los campos de Boquerón, el proyecto de subdivisión consideró la disponibilidad de hijuelas para su arrendamiento a comerciantes o pequeños empresarios con el fin de establecer y explotar hoteles de campaña. En cuanto al de Punta Espora, el mismo surgió hacia 1945 por cuenta de Septimio Yáñez, el mismo propietario del Hotel "Estancia Nueva", favorecido por su situación en el cruce marítimo entre Patagonia y Tierra del Fuego, que comenzó a activarse una vez que se iniciaron las prospecciones petroleras en la zona norte fueguina por parte de la Corporación de Fomento de la Producción.
Pero, de cualquier modo, a éstos como a los más antiguos que permanecían en actividad a uno y otro lado del estrecho de Magallanes los afectó negativamente el progreso, y por diferentes razones fueron cerrando sus puertas. Pasado 1950 la interesante actividad hotelera rural de otrora era en muchos sectores un mero recuerdo de una época diferente y remota. Pero se había cumplido así con un ciclo significativo en la evolución económica y más que todo social en el extenso ámbito territorial de Magallanes. Su quehacer era, definitivamente, parte de la historia del tiempo viejo.

\section{APÉNDICE}

\section{ESTABLECIMIENTOS HOTELEROS CONOCIDOS 1880-1950*}

\section{A. URBANOS}

Nombre

Hotel del Puerto

Hotel Unión

Hotel Comercial

Hotel Universal

Hotel Bella Dalmacia

Hotel de Londres

Hotel Kosmos (Cosmos)

Hotel de Chile

Hotel de la Marina

Hotel Pacífico

Hotel de France

\section{Hotel Royal}

Hotel La Bolsa

Hotel París

Hotel Comercio
Punta Arenas

Punta Arenas

Lugar
Punta Arenas
Punta Arenas
Punta Arenas
Punta Arenas
Punta Arenas
Punta Arenas
Punta Arenas

Punta Arenas

Punta Arenas

Punta Arenas

Punta Arenas

Punta Arenas

Punta Arenas
Propietario** $^{* *}$

Menéndez y Montes

Francisco Aubry

Elías y Mauricio Braun (1885)

Torres y Docherty (1894)

Ríos y Docherty (1894)

Marcos Pivcevic (1894)

Manuel Veiga (1909)

H. Groenewold (1894)

Groenewold y Holtz

Conrado Holtz

E. Schwenger

Carlos Brockow

Julio Biget (1913)

Juan Toth (1916)

¿?

José Burgos (1895)

F. Steffens y Cía. (1898)

Gustavo Malandain (1900)

R. Mounot

Bertrand Baylac (1909)

Esat. vda. de Rouseaux (1910)

Ulises Labat (1913)

Mateo Rajevic (1926)

Martinic y Cvitanic (1942)

J.C. Robins

Dick, Hunter y Cía. (1914)

Ferdinand Garnier

Th. Steffens (1903)

Carlos Brockow

F. Chmielowsky

E. Niebuhr

Fritz Misol (1909)

Otto Schloer

Roque Blaya (1900)

Luis Granella (1906)

L. Swart (1920)

E. Bardin (1914)
Época de funcionamiento****

Década de 1880

Década de 1880

Década de 1890

Década de 1890

Década de 1890

Década de 1890

1894-1950

Décadas de 1890 y 1900

Década de 1890

Década de 1890

Década de 1890-1950

Década de 1890-1930

Década de 1890-1920

1895 en adelante

1895 en adelante

* Número mínimo.

** Únicamente los que han podido ser identificados

*** Estimación 
Hotel Queen's

Hotel Sea Harbour View

Hotel Central

Hotel Alemán

Hotel Imperial

Hotel Caledonia

Hotel Progreso

Hotel Magallanes

Hotel Gran Hotel Chile

Hotel Stadt Hamburg

Hotel Bellevue Hotel

Hotel Plomplón

Hotel Aurífero

Hotel Lion D'or

Hotel Americano

Hotel Helvetia

Hotel Thistle

Hotel White Horse

Hotel Prince of Wales

Hotel Windsor

Hotel Mc Kasill

Hotel Lockery's

Hotel Crown

Hotel White

Hotel Magallanes

Hotel Kap Horn

Hotel Génova

Hotel Roma

Hotel Colón

Hotel Perlá

Hotel Naval

Hotel Inglés

Hotel Económico

Hotel Centenario

(Ex Económico)

Hotel Belgrano

Hotel España

Hotel ¿?

Hotel Carioca

Hotel British

Hotel Bristol

Hotel Asturias

Hotel Royal (segundo)

Hotel Colón (segundo)

Hotel Jadran

Hotel Savoy

(Ex Imperial)

Hotel Valparaíso

Hotel Pilcomayo

Hotel Santucci

Hotel Cervantes

Hotel Grand Hotel

Hotel La Giralda

Hotel Hispano-Americano

Hotel Central

Hotel Alemán

Hotel Chile
Punta Arenas

Punta Arenas

Punta Arenas

Punta Arenas

Punta Arenas

Punta Arenas

Punta Arenas

Punta Arenas

Punta Arenas

Punta Arenas

Punta Arenas

Punta Arenas

Punta Arenas

Punta Arenas

Punta Arenas

Punta Arenas

Punta Arenas

Punta Arenas

Punta Arenas

Punta Arenas

Punta Arenas

Punta Arenas

Punta Arenas

Punta Arenas

Punta Arenas

Punta Arenas

Punta Arenas

Punta Arenas

Punta Arenas

Punta Arenas

Punta Arenas

Punta Arenas

Punta Arenas

Punta Arenas

Punta Arenas

Punta Arenas

Punta Arenas

Punta Arenas

Punta Arenas

Punta Arenas

Punta Arenas

Punta Arenas

Punta Arenas

Punta Arenas

Punta Arenas

Punta Arenas

Punta Arenas

Punta Arenas

Punta Arenas

Punta Arenas

Punta Arenas

Punta Arenas

Punta Arenas

Porvenir

Porvenir
William Kinnaird

Eugenio Noetzel

Miguel Spekoni

Roberto Mulach (1894)

Lilley y Nicol

Cristina vda. de Nicol

Jaramillo y Otey (1936)

J.C. Robins

Gustavo Bragg (1913)

José di Biaggio

Pedro Martinovich (1910)

José A. Menéndez (1914)

Manuel Menéndez

C. Mac Lean

¿?

Conrad Köhler

H. Hutton

Edmundo Groetaers (1907)

Darío Zenteno

Esteban Ferrari

Miguel Pisano (1909)

Max Brandt

Julio Biget

Pedro Villegas

¿?
¿?
¿?
¿?
¿?
¿?
¿?

¿?

¿?

John White

Carlos Strauss

Collin Mac Lean

Anselmo Saldivia

Max Brandt

¿?

E. Cafferata (1908)

José Di Biagio (1917)

¿?

Juan Perlá (1908)

Leoncio López

¿?

¿?

Miguel Radonich

Antonio Sgombich

Vicente Fodich (1916)

Marcos Covich (1916)

Thomas Crighton (1926)

Luis Fernández

Manuel González

Paulino González

Mateo Ivandic

Luis Travini

Juan Jutronic

Alberto Oyarzún

Alfredo Santucci

Sesnic y Carevic

J. Flachier

¿?

Daniel Böhr

Roque Radovich (1916)

Georg Kaiser (1904)

Miguel Radonich
1895 en adelante

1895 en adelante

1895 en adelante

1895 en adelante

1895 en adelante

1895 en adelante

1895 en adelante

Década de 1900

Década de 1900

Década de 1900

Década de 1900

Década de 1900 en adelante

Década de 1900 en adelante

Década de 1900 en adelante

Década de 1900 en adelante

Década de 1900 en adelante

Década de 1900 en adelante Década de 1900 en adelante Década de 1900 en adelante Década de 1900 en adelante Década de 1900 en adelante Década de 1900 en adelante Década de 1900 en adelante Década de 1900 en adelante

Década de 1900

Década de 1900

Década de 1890 en adelante

Década de 1890-1900

Década de 1900

Década de 1900

Década de 1900

Década de 1900

Década de 1900

Cerró en 1910

Década de 1910

Década de 1910

Década de 1910

Década de 1910

Década de 1920

Década de 1920

Década de 1920

Década de 1930

Década de 1930

Décadas de 1930 y 1940

Década de 1930

Décadas de 1930 y 1940

Década de 1910

Décadas de 1920 y 1940

Década de 1930-1940

Década de 1920

Década de 1920

Década de 1930

Década de 1910

Décadas de 1900 y 1910

Décadas de 1900 y 1910 
Hotel Nacional

Hotel Última Esperanza

Hotel ¿?

Hotel ¿?

Hotel ¿?

Hotel ¿?

Hotel ¿?

Hotel ¿?

Hotel ¿?

Hotel ¿?

Hotel ¿?

Hotel ¿?

Hotel Colonial

Hotel Victoria

\section{B. RURALES}

\section{PATAGONIA}

Hotel Cabo Negro

Hotel Cabeza del Mar

Hotel Pozo de la Reina Hotel Laguna Romero Hotel

Hotel ¿?

Hotel Tres Pasos

Hotel Puerto Prat

Hotel ¿?

Hotel ¿?

Hotel ¿?

Hotel ¿?

Hotel ¿?

Hotel Turismo

Hotel ¿?

Hotel ¿?

Hotel ¿?

Hotel ¿?

Hotel ¿?

Hotel ¿?

Hotel ¿?

Hotel ¿?

Hotel ¿?

Hotel ¿?

Hotel ¿?

Hotel ¿?

Hotel ¿?

Pampa Guayrabo

Hotel ¿?

Hotel ¿?

Hotel ¿?

Los Naranjos

Hotel ¿?

Hotel ¿?

Hotel ¿?

Hotel ¿?

Hotel ¿?
Porvenir

Puerto Natales

Puerto Natales

Puerto Natales

Puerto Natales

Puerto Natales

Puerto Natales

Puerto Natales

Puerto Natales

Puerto Natales

Puerto Natales

Puerto Natales

Puerto Natales

Puerto Natales
¿?

Manuel Álvarez

Stubenrauch y Cía.

Braun y Blanchard

J. H. Cox y Cía.

José Díaz

Abrahán Díaz

Pedro Gómez

José Iglesias

Clodomiro Mansilla

Juan Maldonado

Juan de Dios Pedraza

$\dot{i} ?$
$\dot{i} ?$
¿? Hasta década de 1940

Década de 1900 en adelante

Década de 1900 en adelante

Década de 1900 en adelante

Década de 1900 en adelante

Década de 1910

Década de 1910

Década de 1910

Décadas de 1900 y 1910

Década de 1910

Década de 1910

Década de 1910

Década de 1920

Década de 1920
Cabo Negro

Cabeza del Mar

Id.

Id.

Morro Chico

Morro Chico

Id.

Id.

Río Verde

Río Verde

Puerto Cóndor

Puerto Cóndor

Tres Puentes

Tres Puentes

San Francisco

Río de los Ciervos

Río de los Ciervos

Río de los Ciervos

Río de los Ciervos

Río de los Ciervos

Río de los Ciervos

Puerto Natales

Puerto Natales

Ciaike

Tres Brazos

Tres Brazos

Tres Brazos

Guayrabo

Leñadura

Leñadura

Leñadura

Chabunco

Río Seco

Río Seco

Río Seco

Río Seco

Río Seco
Emilio Bays

Luis Friedli (1913)

Marinelic y Brizic

Alec Mac Donald

Meza y Solari

Antonio Baglina

Ruperto Oyarzún

Henry Meade

Charles Finger

Kraft y Cía.

Paul Lemaitre

Rogelio Figueroa

Juana vda. de Figueroa

Santiago Guic

¿?

Carlos Zanzi y Cía.

Paul Lemaitre

Detaille, Henkes y Cía.

Stubenrauch y Cía.

Braun y Blanchard

Carpio Pinto (1913)

Juan Glavic

Margarita Marcic

Pedro Martinic

Pablo Kunica

José Ampuero

Francisco Serón

Esteban Uyevich

Ventura Medina

Ismael Navarro

Gregorio Parra

Alcide Laforest (1903)

Stubenrauch y Cía. (1904)

¿?

Aserradero

Manuel J. Mansilla

José Mihovilovich

Rufino Sirgo

José E. Navarro

Anselmo Serantes

Miguel Pérez

Celestino Foglia

José Gutiérrez

Felipe Marshall

Juan Scepanovic

M. Tadich

Casimiro Mrgudic

Eduardo Mujica
1880 en adelante

Década de $1880 .$.

Década de 1890

Década de 1890

Década de 1890-1930

Década de 1890-1910

Década final siglo

XIX en adelante

Década de $1890 .$.

Década de $1890 \ldots$

Década de $1890 .$.

Década de $1890 . .$.

Década de $1890 . .$.

Década de 1890.

Década de $1890 . .$.

Década de 1940

Década de 1910

Década de 1910

Década de 1910

Década de 1910

Década de 1910

Década de 1910

Década de 1910

Década de 1900

Década de 1890

Década de 1910

Década de 1910

Década de 1910

Década de 1910

Década de 1910

Década de 1910

Década de 1910

Década de 1910

Década de 1930

Década de 1910

Década de 1910

Década de 1910

Década de 1910

Década de 1910 


$\begin{array}{lll}\text { Hotel ¿? } & \text { Chabunco } & \text { David Stambuk } \\ \text { Hotel ¿? } & \text { Morro Chico } & \text { Cipriano Fojo } \\ \text { Hotel ¿? } & \text { Laguna Blanca } & \text { Cipriano Fojo } \\ \text { Cruceros } & \text { Cabeza del Mar } & \text { Antonio Brizic } \\ & & \text { M. y E. Sesnic } \\ \text { Hotel ¿? } & \text { Otway } & \text { Luis Dey } \\ \text { La Leona } & \text { Laguna Blanca } & \text { Cipriano Fojo } \\ \text { La Leona } & \text { Laguna Blanca } & \text { Rivera y Cía. } \\ \text { Carpa Manzano } & \text { Carpa Manzano } & \text { Juan Matesich } \\ & & \text { Jerónima vda. de Ursic } \\ \text { Dinamarquero } & \text { Dinamarquero } & \text { Sesnic y Hassan } \\ & & \text { Dragisevic y Trutanic } \\ \text { Morro Chico } & \text { Morro Chico } & \text { Francisco Marinkovic } \\ \text { Río Verde } & \text { Río Verde } & \text { José Laguía } \\ \text { Los Robles } & \text { Río Rubens } & \text { Rafael Ovando M. } \\ \text { Agua Fresca } & \text { Agua Fresca } & \text { José Rajcevic } \\ \text { Alcalde Sanhueza } & \text { San Gregorio } & \text { ¿? }\end{array}$

\section{TIERRA DEL FUEGO}

Río del Oro
Casa de Lata
Los Morros
Discordia
Baquedano
Bahía Inútil

Cañadón
Bahía Felipe
Estancia Nueva
Punta Espora

\section{FUENTES DE CONSULTA}

a) Libros y guías

BEERBOHM, JULIUS. 1879. Wanderings in Patagonia. London.

BIRD, JUNIUS B. 1993. Viajes y Arqueología en Chile Austral. Ediciones de la Universidad de Magallanes. Punta Arenas.

CHAMORRO, CLAUDIO. 1936. Bajo el cielo austral. Punta Arenas.

CHILDS, HERBERT. 1997. El Jimmy Bandido de la Patagonia. Ediciones de la Universidad de Magallanes. Punta Arenas.

COMPAÑÍA TELEFÓNICA DE MAGALLANES. 1942. Guía de Teléfonos Punta Arenas Puerto Natales Cabeza del Mar Morro Chico. Punta Arenas.

- 1952. Guía de Teléfonos Magallanes. Punta Arenas.

DIXIE, FLORENCE. 1996. A través de la Patagonia. Ediciones de la Universidad de Magallanes. Punta Arenas.

FUENTES RABÉ, CARLOS. 1923. Tierra del Fuego, 2 tomos. Valdivia.

GÓMEZ IZQUIERDO, JERÓNIMO. 1942. Tierras Australes. La Patagonia, Tierra del Fuego. Empresa Editorial Bell. Buenos Aires.

JERICEVICH, GARRALDA Y CÍA. (Editores). 1926. Comercio e Industria de Magallanes. Punta Arenas.

KRAMARENKO Y SACKEL. 1936. Colonizadores de Tierra del Fuego. Punta Arenas.

LAMING, ANNETTE. 1957. En la Patagonia confín del mundo. Editorial del Pacífico. Santiago.

MARTINIC B., MATEO. 1971. José Nogueira, primer pionero y hombre de fortuna de la antigua Colonia de Maga-

b) Diarios y 1929. y 1922 .
Década de 1910

Década de 1910

Década de 1910

Década de 1910

Década de 1910

Década de 1910

Década de 1890

Década de 1910

Década de 1930

Década de 1910

Década de 1940

Década de 1940

Década de 1930

1930 en adelante

Década de 1930 ...

Década de 1930...

Década de 1900

Década de 1910

Década de 1910

Década de 1910

Década de $1900 . .$.

Década de 1910

Década de 1930

$1939 \ldots$

1941 ...

1945.

llanes, Anales del Instituto de la Patagonia, volumen II. Punta Arenas.

- 1985. Última Esperanza en el tiempo. Ediciones de la Universidad de Magallanes. Punta Arenas.

- 1988. Punta Arenas en su primer medio siglo 18481898. Edición del autor. Punta Arenas.

- 1992a. Historia de la Región Magallánica. Santiago. - 1992b. La población magallánica a lo largo de un siglo. Anales del Instituto de la Patagonia, Serie Ciencias Humanas, volumen 21. Punta Arenas.

NAVARRO AVARIA, LAUTARO. 1908. Censo Jeneral del Territorio de Magallanes. Punta Arenas.

S/AUTOR. 1905-07. Libro de Cuentas, Hotel Tres Pasos. Manuscrito inédito.

S/AUTOR. 1914. Rol de Avalúos Urbano y Rural del Territorio de Magallanes. Punta Arenas.

SIEVERS, HUGO K. 1948. Rutas Patagónicas. Editorial Orbe. Santiago.

TSCHIFFELY, A. F. 1998. Por este camino hacia el sur. Un viaje a través de la Patagonia y Tierra del Fuego. Editorial El Jagüel. Buenos Aires.

ZORRILLA, MANUEL. 1909. Guía de Magallanes en 1909. Punta Arenas.

Diario El Magallanes, Punta Arenas, años 1894-1899

Diario El Obrero, Punta Arenas, año 1898.

Diario El Comercio, Punta Arenas, años 1900-1920.

Diario The Magellan Times, Punta Arenas, años 1914

Diario El Mercurio, Santiago, edición del 12-IX-1933. 